\title{
CARPINTERÍA DE ARMAR CON LACERÍA EN IGLESIAS DE LA REGIÓN DE MURCIA. CONCEPTOS BÁSICOS Y CARACTERÍSTICAS DE ESTAS TECHUMBRES DE MADERA
}

\section{STRUCTURAL CARPENTRY WITH “LACERÍA” IN CHURCHES OF THE REGION OF MURCIA. BASIC CONCEPTS AND CHARACTERISTICS OF THESE WOODEN CEILINGS}

\author{
Pedro Enrique Collado Espejo \\ Universidad Politécnica de Cartagena
}

\begin{abstract}
RESUMEN
A principios del siglo XVI, el Reino de Murcia experimenta un notable aumento de población que conlleva la construcción de numerosas iglesias. En general, estos nuevos templos se caracterizarán por el sistema de techumbre de madera a base de carpintería de armar con lacería. En muchos textos, a estas construcciones históricas se les ha denominado como "iglesias mudéjares" o "iglesias moriscas", y su tipología ha sido relacionada con los modelos granadinos, sevillanos, levantinos (por el uso de arcos transversales o diafragma) o castellanos, dependiendo del autor que analizara estas construcciones. El presente texto pretende exponer las características formales y constructivas de estas iglesias y sus techumbres de madera, los sistemas de aprendizaje y trabajo de los autores de las cubiertas (bajo el control de los gremios de carpinteros y regulado por las correspondientes ordenanzas), y justificar por qué no se deben atribuir estas edificaciones a carpinteros mudéjares o moriscos sino a carpinteros procedentes de áreas de Castilla y por qué deberíamos denominar estos trabajos como carpintería de lazo. Con ello, se pretende contribuir al conocimiento y difusión de estas magníficas soluciones estructurales y decorativas de carpintería de armar, con lacería, que aún se conservan en nuestra Región, contribuyendo así a su conservación.
\end{abstract}

Palabras clave: Techumbres de madera, carpintería de lazo, carpintería de armar, iglesia, Región de Murcia

\begin{abstract}
At the beginning of the 16th century, the Kingdom of Murcia experienced a notable increase in population that led to the construction of numerous churches. In general, these new temples will be characterized by the carpentry-based wooden ceilings system of structural carpentry with lacework. In many texts, these historical constructions have been called "mudejar churches" or "moorish churches", and their typology has been related to the Granada, Sevilla, Levantine (due to the use of transverse arches or diaphragm) or Castilian models, depending on the author who analyzed these constructions. This text aims to expose the formal and constructive characteristics of these churches and their wooden ceilings, the learning and work systems of the authors of the ceilings (under the control of the carpenters' unions and regulated by the corresponding ordinances) and justify why these buildings should not be attributed to "mudejar" or moorish carpenters but to carpenters from areas of Castile and why we should call these works as laced carpentry. With this, it is intended to contribute to the knowledge and dissemination of these magnificent structural and decorative carpentry solutions to be assembled, with lacework, which are still preserved in our Region, thus contributing to their conservation.
\end{abstract}

Key words: Wooden ceilings, laced carpentry, structural carpentry, church, Region of Murcia 


\section{ANTECEDENTES. EL SIGLO XVI, REPOBLACIÓN Y EVANGELIZACIÓN DEL TERRITORIO MURCIANO. LAS NUEVAS ERMITAS}

A mediados del siglo XIII se produce la reconquista cristiana y delimitación del antiguo Reino de Murcia, que inicialmente comprendía no solo los límites de la actual Región de Murcia sino que incluía parte del sureste de la actual provincial de Albacete, algunas localidades de la provincia de Jaén (Alcalá la Real y la Sierra del Segura), y las alicantinas ciudades de Villena y Sax. Desde entonces, y hasta la reconquista cristiana del reino nazarí de Granada, en 1492, los intentos de repoblación y asentamiento de población cristiana en este territorio habían tenido poco éxito. La inseguridad generada por las continuas incursiones de tropas musulmanas, la inestabilidad política por las disputas territoriales de la nobleza (como la conocida como "Guerra de los dos Pedros", entre 1356 y 1369), y las varias epidemias de peste, dejaron a finales de siglo XIV y principios del XV amplias zonas muy despobladas, como los territorios de Caravaca y Cehegín.

Con la reconquista de Granada y la consolidación de la unión de las Coronas de Castilla y Aragón, llegará la estabilidad política y social al Reino de Murcia, con lo que nuevamente se inicia un periodo, ahora exitoso, de repoblación de este territorio. La Comarca del Noroeste será un ejemplo de cómo se potencia y desarrolla este notable crecimiento de población, en este caso bajo la estructura organizativa, protección y tutela de la Orden Militar de Santiago. En general, este aumento de población del Reino de Murcia se asentará en el establecimiento de los castellanos que habían participado inicialmente en la protección y consolidación de la frontera con el reino nazarí de Granada y la reconquista posterior de este, así como en la llegada de nuevos pobladores procedentes de Castilla y población musulmana procedente de al-Andalus, que se dedicará, en los núcleos rurales, principalmente a la agricultura y la ganadería (como en el Valle de Ricote, la zona de mayor concentración de moriscos en esta época en el antiguo Reino de Murcia); y en el ámbito urbano a la industria de la seda (Molina, 2014: 195), aunque también llegarán albañiles, mercaderes y artesanos que potenciarán industrias como la de la cerámica, la orfebrería, el calzado...

La consecuencia inmediata de este paulatino aumento de población será el importante desarrollo urbano que experimentarán, a partir del siglo XVI, ciudades como Caravaca de la Cruz, Cehegín, Lorca, Totana..., que vivirán un notable crecimiento fuera del recinto amurallado, con nuevas barriadas, así como la aparición de pequeños núcleos de construcciones en las zonas de huerta (Gutiérrez-Cortines y Griñán, 1996). Todo este proceso, que en el caso del territorio murciano será tutelado principalmente por la Orden de Santiago y que pretende consolidar y unificar formal, social y culturalmente los territorios, conllevará la necesidad de construir edificios de culto cristiano (iglesias y ermitas) que, además de resolver la demanda de servicios religiosos de la numerosa población cristiana, debe servir para la necesaria evangelización y asimilación sociocultural de la población musulmana, a la que ahora se identificará como "morisca" (más adelante comentaremos la diferencia entre mudéjar y morisca). Por ejemplo, en Caravaca de la Cruz se construirá la ermita de la Purísima Concepción (consagrada en 1556), la de San Sebastián (popularmente conocida como ermita del Santo), y las de San Jorge y San Bartolomé (que actualmente no se conservan). En Lorca, se levantará el convento de La Merced (actual edifico administrativo del Ayuntamiento de Lorca), el convento de Santo Domingo, y de las ermitas de Ntra. Sra. de los Remedios, San Lázaro, Santa Quiteria y Ntra. Sra. de Gracia (Belda y Marín, 1999; 104). En Totana, la iglesia de Santiago (consagrada en 1567) y el santuario de Santa Eulalia de Mérida (conocida popularmente como La Santa y cuya configuración principal de realiza a finales del siglo XVI sobre una pequeña ermita del siglo XV). En Mazarrón, la iglesia de San Andrés (construida en torno a 1543, con una configuración distinta a la que actualmente presenta), y la ermita de Ntra. Sra. de la Concepción (que en el XVII se amplía para convertirse en la actual iglesia conventual de la Purísima) Y en el entorno urbano de Cehegín las ermitas de Ntra. Sra. de La Concepción (consagrada en 1556), Ntra. Sra. de La Soledad (1595), la del Santísimo Cristo del Milagro (1595) y la ermita de San Esteban (1526, actual convento de San Esteban). Así mismo, en la huerta (vega del río Argos) se construirán las ermitas de San Sebastián (1507), Santa Barbara, San Ginés, San Agustín (1526) y el santuario de la Virgen de la Peña. La construcción y ubicación de todas estas ermitas tenía el objetivo de proteger a la población y a sus cultivos de todo tipo de males, como las epidemias de peste y cólera, las sequías, las plagas, las inundaciones, etc., así como cumplir con unas mínimas funciones específicamente religiosas (De la Ossa, 1998). 

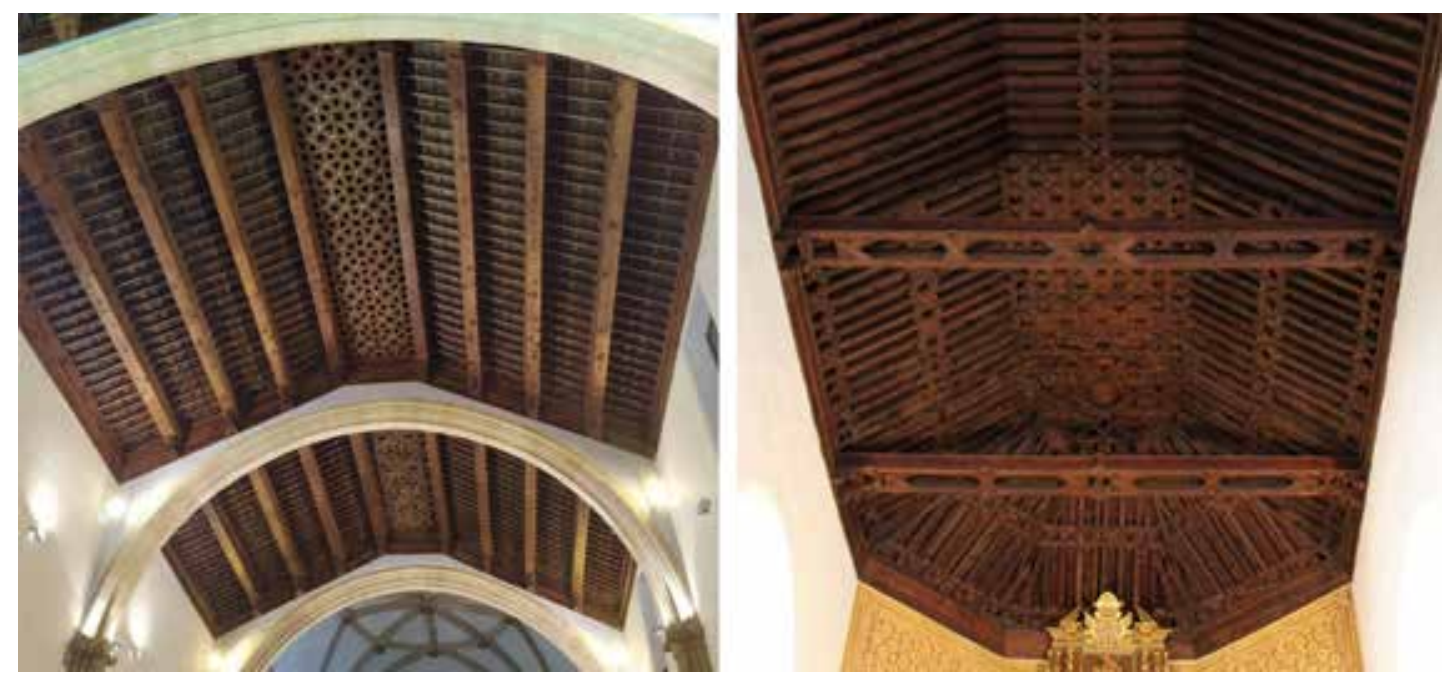

FIGURA 1. Vistas generales de las techumbres de madera con lacería de la Iglesia de la Purísima Concepción, en Caravaca (a la izquierda) y de la Iglesia de Santiago, en Totana (a la derecha)

Por otra parte, hay que destacar que en la mayoría de los casos, estas ermitas tienen un origen similar: serán promovidas y construidas por una cofradía fundada con un fin religioso y social y, en algunos casos, asistencial, al construir también, anexo al nuevo templo, un hospital (edificio que en todos los casos no se ha conservado), para el cuidado y atención de enfermos y pobres. Así, en Caravaca de la Cruz será la Cofradía de Ntra. Sra. de La Concepción y San Juan de Letrán la que construirá la iglesia de La Purísima Concepción y anexo, un hospital de Caridad (Collado, 2020). En Mula, la Cofradía de La Purísima Concepción construye el hospital de San Pedro y la iglesia (terminada en 1577), que actualmente forma parte del convento de San Francisco (Collado y Fernández, 2018). En Lorca, la Cofradía de la Santa Vera Cruz y Sangre de Jesucristo levantará el convento de Santo Domingo. En Cehegín, la Cofradía de la Virgen de Los Dolores construirá la ermita de Ntra. Sra. de La Soledad (que servirá para ordenar y consolidar la trama urbana del barrio del Cubo); la Cofradía de la Preciosísima Sangre de Cristo levantará la ermita del Santísimo Cristo del Milagro, en el popular barrio del Coso; y la Cofradía de Ntra. Sra. de La Concepción (que se constituye en 1534), construirá un hospital de Caridad y, anexo a este, la ermita de Ntra. Sra. de La Concepción (Collado, 2019), que marcará el límite del desarrollo urbano del llamado Arrabal de las Eras (Molina, 2002).

\section{ARQUITECTURA TRADICIONAL POPULAR Y TECHUMBRES DE MADERA}

Los nuevos centros de culto cristiano, que actualmente se consideran iglesias cuando están en entornos urbanos y ermitas en entornos de huerta, serán construidos con materiales y sistemas constructivos propios de la llamada "arquitectura tradicional popular". Por tanto, se utilizarán materiales tradicionales como la tierra, la cal, el yeso, la madera (principalmente el pino), el ladrillo macizo y los mampuestos de piedra; es decir, materiales fáciles de obtener en el entorno y de bajo coste. Para los sistemas constructivos se recurrirá, principalmente, a la estructura de muros de carga de tapia (tierra compactada con adicción de cal) y/o muros de mampostería, ladrillo macizo para la realización de arcos, bóvedas y campanarios, dejando el uso de sillares de piedra y trabajos de cantería solo para algunas columnas y para las portadas, reservando la madera de pino para los medios auxiliares (andamiajes, apeos y cimbras) y para los entramados de las cubiertas. En algún caso puntual, como en la antigua ermita y hoy iglesia de Ntra. Sra. de La Concepción, en Cehegín, para la fabricación de las dovelas de los arcos transversales se recurrirá al uso de mortero de yeso (Marín, 1999), simulando el empleo de sillares de piedra. Como vemos, materiales y sistemas constructivos, que incluyen apoyos directos y ensamblajes históricos característicos, con una larga tradición de empleo entre alarifes, maestros de obra y albañiles.

En cuanto a las características arquitectónicas y funcionales de estas construcciones religiosas, destaca la solución de planta rectangular y dimensiones reducidas, con una nave central amplia y laterales muy estrechas y poco iluminadas (apenas uno o dos óculos o pequeños 

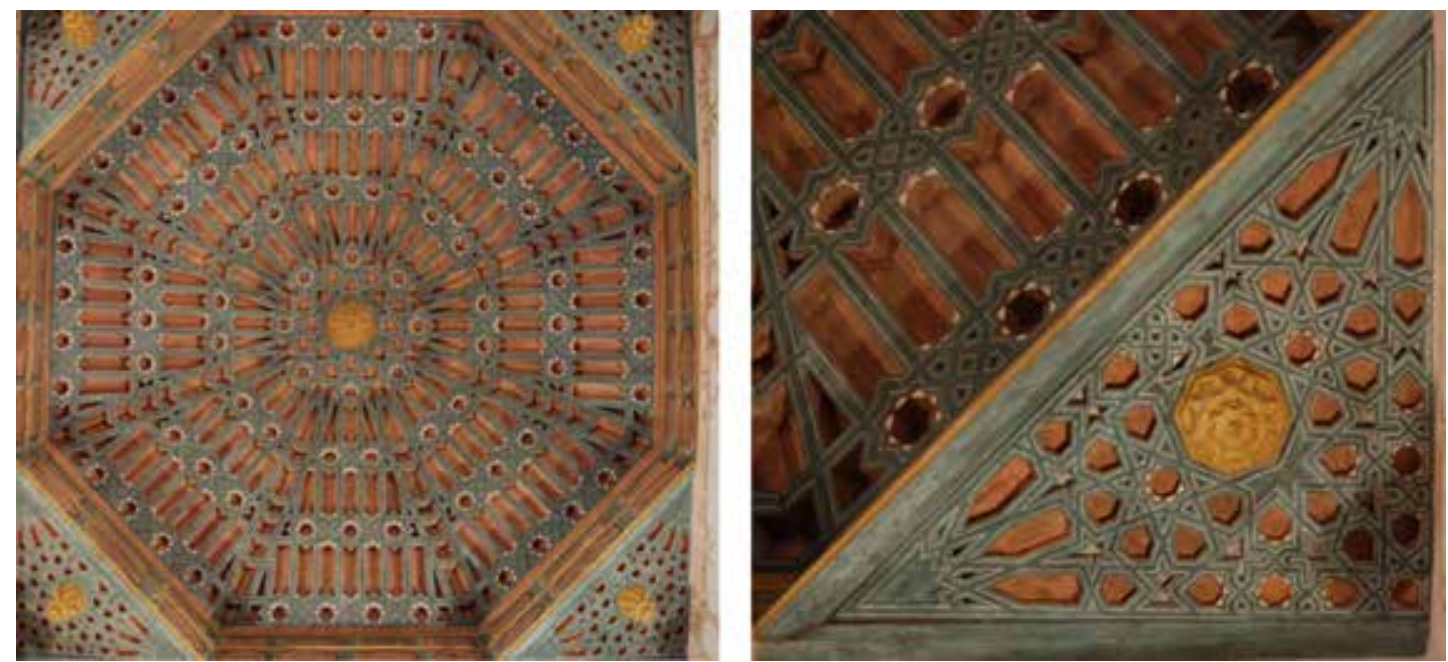

FIGURA 2. A la izquierda, vista general de la cúpula ochava que cubre el altar mayor de la Iglesia de Ntra. Sra. de la Concepción, en Cehegín. A la derecha, detalle de una de las pechinas.

huecos de ventana y una única puerta de acceso), un zaguán de entrada, cubierta a dos aguas y pocos elementos decorativos (las decoraciones a base de molduras de yeso y policromías que ahora encontramos en alguna iglesia/ermita se deben principalmente a añadidos del siglo XVIII). A los pies de estos edificios de culto se construirá un coro o tribuna (que en ocasiones incorporará la vivienda del ermitaño), mientras que para realzar el protagonismo del altar mayor sobre la nave central, este se elevará tres o cinco escalones. Al exterior, las fachadas serán lisas, con un carácter muy austero, con contrafuertes (especialmente cuando la estructura del templo se resuelve interiormente con arcos transversales), y solo destacará la torre-campanario, que en muchos casos será reformada en el XVIII para darle mayor protagonismo como elemento sobresaliente y que identifica el templo en la trama urbana medieval.

Pero lo más destacable de estas construcciones es la techumbre de madera con la que se cubrían, que se resuelve con carpintería de armar y, en muchas de las que han llegado a nuestros días, decorada con lacería. Pérez Sánchez, que denomina estas construcciones como "iglesias moriscas" defiende que "con un paralelismo casi absoluto con lo granadino inmediato a la Reconquista, la arquitectura rural de Murcia pugnará entre el gótico y el renacimiento incipiente y la nota más rica y personal la darán los techos de armadura de pares y nudillo, o de dos vertientes sobre arcos transversales, casi lo único de carácter artístico en estos pobres templos, tan en abierto contraste con las otras grandiosas creaciones del renacimiento urbano a la italiana" (1960: 93). En el caso del uso de arcos transversales o diafragma, la nave central se resolverá con varios tramos (que en algunos casos se irán añadiendo conforme aumente la demanda de espacio del templo), claramente delimitados por estos arcos, que serán apuntados (de tradición gótica, como en las ermitas de San Bartolomé, en Ulea y en Caravaca, y San Onofre, en Alguazas) o de medio punto (traza renacentista, como en La Concepción, en Caravaca y Cehegín, Ntra. Sra. de Loreto, en Algezares-Murcia, o San Roque, en Yecla), y sobre estos apoyará la techumbre de madera cuyos faldones se resolverán con la técnica de cinta y saetino y, en la zona central de la cubierta, un falso almizate decorado con lacería. En este aspecto hay que destacar la configuración espacial de la iglesia de Ntra. Sra. de la Concepción, en Cehegín donde "la techumbre no descansa directamente sobre los arcos, sino que sobre éstos se eleva un cuerpo macizo que duplica casi la altura, desde el capitel. Sobre este cuerpo liso, se apoyan las vigas, y el espacio queda asi compartimentado en espacios cuadrados, y la vista interrumpida sucesivamente por lo macizo, creando unos fuertes contrastes de luz y sombra" (Pérez, 1960: 101). Por tanto, en Cehegín el que accede al templo no puede contemplar, con cierta continuidad longitudinal, la techumbre de la nave central y, lo que es más interesante, hasta que no llega al altar mayor y levanta la mirada, no puede asombrarse y disfrutar de la armadura ochava (ocho faldones sobre base cuadrada) de madera con que se cubre este espacio tan importante del templo, un magnífico trabajo de carpintería de armar, con limas mohamares, decorada con lacería 
(enriquecida con policromía) con un diseño de entrelazados típicos del arte musulmán, que van desarrollando estrellas de ocho, y cuatro piñas de mocárabes dorados (una central, en el almizate y el resto en las pechinas correspondientes); además de ser un ejemplar único en la Región de Murcia, pues la armadura ochava que actualmente cubre el altar mayor de la iglesia de Pasos de Santiago, en Murcia, en realidad es una reconstrucción de mediados del siglo XX.

Más adelante profundizaremos en el concepto "iglesia mudéjar/morisca" así como en las soluciones de techumbre con arcos transversales o con par y nudillo (una tipología que aún se conserva en las iglesias de San Andrés, en Mazarrón, y de Santiago, en Totana, así como en la ermita de Santa Eulalia de Mérida, también en Totana).

\section{MUDÉJARES Y/O MORISCOS. TECHUMBRES Y/O ARTESONADOS}

Cuando visitamos alguno de estos templos, tanto en la Región de Murcia como en el resto de España, y leemos la placa en fachada (o el folleto turístico) que nos informa de los orígenes y características patrimoniales de estas construcciones, solemos encontrarnos con términos y definiciones como "artesonado mudéjar", "iglesia mudéjar" (o "morisca", como hemos comentado que las define Pérez Sánchez), "techumbre morisca"... También cuando recurrimos a su declaración de bien de interés cultural, con categoría de monumento, podemos leer "templo de techumbre mudéjar" (Decreto n²6/1995), o que se destaque su "soberbio armazón morisco (...), siendo el artesonado, en general. una de las más bellas muestras del arte mudéjar murciano" (R.D. 2430/1980). Por tanto, se estaría atribuyendo la autoría, al menos de la realización de las techumbres de madera, a moriscos y/o mudéjares, sin tener en cuenta la diferencia entre unos y otros, el contexto histórico y sociocultural en que se realizaron estas construcciones ni las condiciones laborales en las que trabajaban los encargados de levantar estas iglesias y sus cubiertas de madera (alarifes, maestros de obras, oficiales, carpinteros, pintores, aprendices...). Afortunadamente, en los últimos años la historiografía ha aumentado notablemente el conocimiento que se tenía sobre estos condicionantes socioculturales y, en el caso de las techumbres resueltas con carpintería de armar y lacería, se ha avanzado mucho en el entendimiento de su evolución y desarrollo. Así mismo, la participación de carpinteros moriscos y/o mudéjares en el trazado y realización de estas techumbres, especialmente a partir de mediados del siglo XVI, se ha puesto en entredicho y, en el caso del antiguo Reino de Murcia, con más razón.

En primer lugar, debemos recordar la diferencia entre morisco y mudéjar. El primer término se refiere a los musulmanes que, a partir del año 1502, en el territorio bajo la jurisdicción de la Corona de Castilla (que incluía el Reino de Murcia) y de 1525, en la Corona de Aragón (que incluía el Reino de Valencia), son obligados a renunciar a su fe y costumbres y a convertirse al cristianismo (se les llamará también "cristianos nuevos"), para poder permanecer en la Península; aunque finalmente Felipe III decretará la expulsión de toda la población morisca, que se realizará de forma escalonada entre 1609 y 1613 (siendo los últimos los del Reino de Murcia). Mudéjares es la denominación de los musulmanes que, una vez reconquistado, vivían en territorio cristiano, normalmente concentrados en morerías (barrios concretos de las ciudades), pero a los que se les permitía mantener su religión, ritos y costumbres a cambio de pagar unos impuestos especiales y de asumir determinadas limitaciones en sus relaciones con los "cristianos viejos" (para muchos historiadores, los mudéjares/moriscos coexistieron más que convivieron con los cristianos), y que serán obligados a convertirse en moriscos y finalmente expulsados. Por tanto, en el caso de los templos murcianos del XVI-XVII el término mudéjar no sería el más apropiado, en todo caso, morisco, aunque como comentaremos, las condiciones sociolaborales y de especialización necesarias para realizar estas techumbres hacen muy difícil su atribución a carpinteros moriscos, Además, en la Región de Murcia no hay techumbre de madera resuelta con carpintería de armar y lacería ataujerada (tipología en la que los elementos que forman la decoración de entrelazados formando la lacería están clavados a tableros sujetos a la estructura), de claro origen musulmán. En el caso murciano, todos los templos que presentan armaduras originales con lacería, al menos las que actualmente se conservan (La Purísima Concepción, en Caravaca, Ntra. Sra. de la Concepción, en Cehegín, Ntra. Sra. de Loreto, en Algezares-Murcia, San Andrés, en Mazarrón, Santiago y Santa Eulalia 
de Mérida, ambas en Totana, y San Onofre, en Alguazas) presentan la solución apeinazada (los maderos estructurales conforman también la decoración, por lo que las piezas del entrelazado de la lacería forma parte de los elementos estructurales de la techumbre), una solución típica de la carpintería de armar española. Además, los maestros carpinteros y sus oficiales tenían prohibido tomar aprendices mudéjares (Nuere, 2000: 21), como se recoge en las Ordenanzas de carpinteros de lo blanco de Sevilla (similares a las de Toledo y Córdoba), de principios del siglo XVI (recopiladas en 1519 de las antiguas ordenanzas de los alarifes de 1443, y reimpresas en 1632) al determinar "que no se tome aprendiz que no sea christiano y de linaje de christianos limpio". Por tanto, lo más probable es que los trabajos de carpintería de armar con lazo realizados en el antiguo Reino de Murcia en el siglo XVI fueran realizados por maestros carpinteros y oficiales procedentes de áreas castellanas (Cantero, 2011:140. Collado, 2019: 307).

En realidad, la participación de moriscos en la construcción de techumbres con lacería en el territorio Murcia ya había sido cuestionada por la profesora Gutiérrez-Cortines cuando comenta que "tal vez haya que advertir sobre la tendencia a atribuir su construcción a una población morisca, cuando en realidad, puede señalarse que, al margen de su origen, en el siglo XVI era un modelo perfectamente asimilado por la población, conocido por albañiles y carpinteros y que sirvió como solución útil, realizada por profesionales de muy diversa procedencia, pero no especialmente por moriscos" (Gutiérrez-Cortines, 1987: 435), así como por los profesores Belda Navarro y Hernández Albaladejo para los que "si bien fueron el resultado de una práctica secular muy bien trabajada por determinados artesanos, no tiene por quéestar vinculada a una etnia particular como la población morisca" (Belda y Hernández, 2006: 93)

En cuanto al concepto "arte mudéjar", hay que recordar que empieza a tomar forma a partir del discurso de ingreso en la Real Academia de Bellas Artes de San Fernando de José Amador de los Ríos, leído el 19 de junio de 1859 y con título "El estilo mudéjar en arquitectura", en el que defendió la existencia de este arte como maridaje del arte cristiano e hispanomusulmán, además de ser "el único estilo del que podemos enorgullecernos los españoles". Más reciente es la definición del catedrático Borrás Gualis como la "pervivencia del arte islámico en la España cristiana, un fenómeno social y artístico privativo de la historia y de la cultura españolas" (Borrás, 2006: 298), destacando dos aspectos básicos para este historiador: la primacía de la ornamentación y la pervivencia de estructuras derivadas del arte islámico. La preeminencia que tiene la ornamentación en estos trabajos es clara, sin embargo atribuir la traza y diseño estructural a un origen musulmán es algo muy cuestionado en la actualidad.

La inclusión del término "mudéjar" podría entenderse como que este estilo artístico sería exclusivo de constructores mudéjares, algo que desde el primer momento será negado por arquitectos como Vicente Lampérez, Leopoldo Torres Balbás, Fernando Chueca y más recientemente, por Enrique Nuere (gran especialista y divulgador de la carpintería de armar española), por considerar que tanto cristianos (especialmente) como judíos (algo menos) participaron del desarrollo de este arte. Y esto será especialmente así cuando se trata de trabajos de carpintería de armar (con o sin lacería), enfatizando, en contra de la opinión de Borrás, que las estructuras (trazado y técnica constructiva) son cristianas. Para Enrique Nuere "fueron los carpinteros castellanos quienes sistemáticamente integraron la decoración típicamente islámica en sus armaduras de cubierta, mientras los nazaries preferían emplear su característica geometría principalmente con funciones decorativas, lo que no impedia que en alguna ocasión también la emplearan en carpinterías estructurales" (Nuere, 2010: 32). Así mismo, historiadores murcianos defienden que estas carpinterías "si bien fueron el resultado de una práctica secular muy bien trabajada por determinados artesanos, no tiene por qué estar vinculada a una etnia particular como la población morisca" (Belda y Hernández, 2006: 159), así mismo, "en el siglo XVI era un modelo perfectamente asimilado por la población, conocido por albañiles y carpinteros y que sirvió como solución útil, realizada por profesionales de muy diversa procedencia, pero no especialmente por moriscos" (Gutiérrez-Cortines, 1987: 435). Por tanto, la tendencia tan arraigada de atribuir estas techumbres de madera a la población mudéjar y/o morisca debería corregirse y sólo sería aceptable el concepto "techumbre mudéjar" aclarando, especialmente en los ámbitos académicos y legislativos (en las declaraciones de Bien de Interés Cultural con categoría de monumento), que se hace con base en el estilo artístico y no como referencia a los maestros carpinteros autores de estos trabajos. 


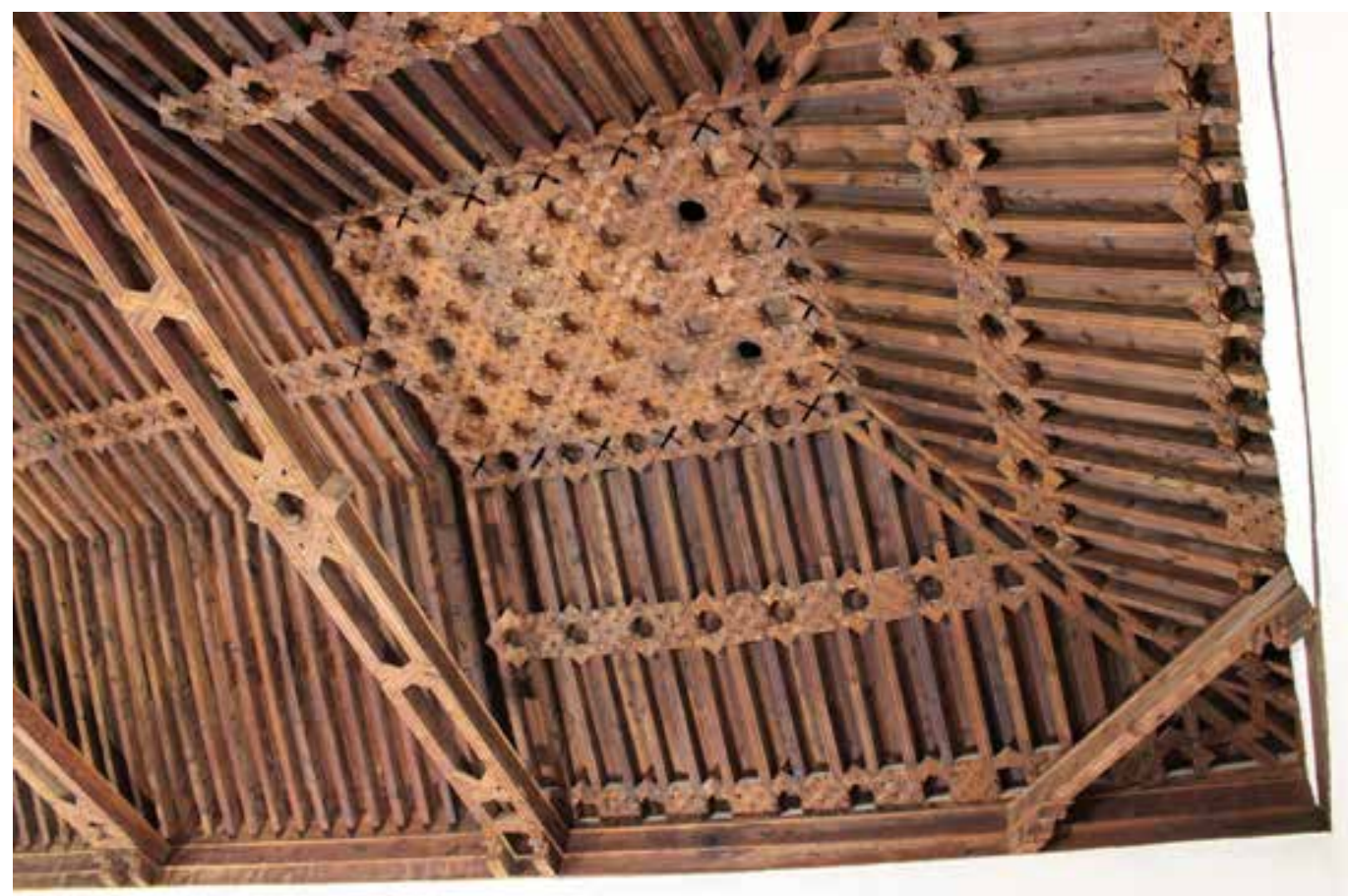

FIGURA 3. Techuimbre de la Iglesia de Santiago, en Totana, en la zona que cubre el coro, a los pies del templo. Destaca la lacería con desarrollo de la estrella de ocho en almizate y la lima mohamar.

Como las techumbres murcianas resueltas con carpintería de armar y lacería son trabajos realizados en el siglo XVI, el análisis de las técnicas y condiciones de trabajo de los maestros carpinteros y sus ayudantes, nos permiten considerar que la participación de carpinteros mudéjares y/o moriscos en estas iglesias es bastante improbable. Para poder trazar y desarrollar estos trabajos, el "carpintero de lo blanco" (por el uso, principalmente, de madera de pino), o "alarife", como se les denominaba en la Edad Media a estos carpinteros (aunque con este término se reconocía también, por sus funciones, a los actuales arquitectos o aparejadores municipales), debía tener unos conocimientos en construcción $\mathrm{y}$, especialmente, en geometría que en el siglo XVI no estaban al alcance de cualquiera. Por ejemplo, las ordenanzas de Sevilla, recopiladas en 1519, definen a los alarifes "como omes sabidores, que son puestos por mandado del Rey, para mandar fazer derecho acuciosamente, y con gran bemencia deven ser acatados, aquellos que fueren escogidos para ser alarifes: $y$ que ayan en si a lo menos estas cosas, que sean leales, y de buena fama, y sin mala cobdicia; que ayan sabiduria de Geometría, $y$ entendidos de fazer engenios, $y$ otras sotilezas: $y$ que ayan sabiduría para juzgar los pleytos derechamente por su saber, o por uso de luengo tiempo: $y$ que sean mansos, $y$ de buena palabra a los que ovieren de juzgar: $y$ que metan paz entre ellos: $y$ que juzguen por mandado del Alcalde, con vista, y acuerdo de omes bueno, que sean de al arte de su menester: $y$ sobre todo, que teman a Dios y al Rey". Por tanto, para ser alarife había que tener "sabiduria de Geometría" $\mathrm{y}$, cuando además de maestro carpintero se le reconocían otras atribuciones (como tasar y juzgar pleitos relacionados con la construcción), parece obvio que desde comienzos del siglo XVI, con la reconquista cristiana y la conversión obligada de los mudéjares, este cargo lo ocuparían los "cristianos viejos", como así ocurrió definitivamente desde principios del XVII con la expulsión de los moriscos.

Además, para diseñar la estructura y ornamentación de estas techumbres y poder cortar y ensamblar correctamente las numerosas piezas que componían estos trabajos, el maestro carpintero seguía unas reglas de traza y construcción que había asimilado gracias a un estricto sistema jerarquizado de aprendizaje y formación, que duraba varios años, y que estaba controlado por los gremios de carpinteros a través de las ordenanzas. Unos conocimientos técnicos que eran transmitidos de maestros a aprendices y oficiales en talleres, en muchas ocasiones de padres a hijos, y de una manera práctica y verbal (en esta época, 
saber leer y escribir estaba al alcance de muy pocos), creándose una estructura de personas emparentadas que permitía transmitir y proteger los secretos del arte de la construcción, en general, y de la carpintería de lo blanco, en particular. Unas reglas que conocemos gracias a los tratados de Diego López de Arenas ("Breve compendio de la carpintería de lo blanco y tratado de alarifes", publicado en 1633), de Fray Andrés de San Miguel (un manuscrito que se conserva en la biblioteca de la Universidad de Texas), y de Rodrigo Álvarez ("Breve compendio de la carpintería y Tratado de lo blanco con algunas cosas tocantes a la geometría, y puntas del compas", de 1699). Tratados ampliamente estudiados y divulgados por Enrique Nuere, que nos muestran la técnica constructiva de la carpintería de armar y de lazo. Con este sistema de control corporativo del oficio de carpintero, muy consolidado a partir del siglo XV (como ocurrirá también con el resto de actividades artesanales, controladas por los gremios), se conseguía que prevaleciera "el papel del carpintero constructor de estructuras carpinteras de edificación sobre el del albañil que levantaba muros y bóvedas"; unos trabajos que "siempre estuvieron reglados por el uso de una serie de plantillas, en forma de triángulos rectángulos" (Nuere, 2015: 135). Es decir, toda esta manera de cubrir y embellecer edificios, que deberíamos identificar como carpintería de lazo, es posible gracias al uso exclusivo de una serie de cartabones que el maestro carpintero debía trazar a partir de dos datos: primero el diseño del lazo que desea, y después (pero relacionado con éste), el ancho de la estancia a cubrir, que le permitía calcular la inclinación de la cubierta, con la longitud de los pares y todo lo que ello conllevará. Por ello, la máxima categoría que podía alcanzar un carpintero de lo blanco era la de "iumétrico", por la importancia del conocimiento de las reglas de la geometría y uso de los cartabones que rigen estos trabajos, estando capacitado para proyectar en cualquier circunstancia. En una categoría inferior estaba el "lazero", carpintero que es capaz de trazar techumbres con lazo pero no ha acreditado (mediante examen) capacidad para calcular y trazar cualquier tipo de techumbre (en las ordenanzas de Granada solo se le exigía saber realizar "una quadra ochavada de lazo"), por lo que su trabajo se basaba en el uso de las reglas y modelos de uso corriente (cartabones de armadura y cartabones de lazo) con la geometría idónea en función al diseño a realizar. Este sistema gremial de aprendizaje estaba muy reglado y sus antecedentes son los talleres musulmanes pero, como se ha comentado, a partir de la reconquista cristiana las ordenanzas de carpinteros especifican que para entrar como aprendiz era necesario ser "cristiano limpio" y se impedía a esclavos o negros, aunque hubiesen aprendido el oficio, ser examinados para oficiales, siendo la duración media de formación del aprendiz de unos seis años (López, 2016). Por ejemplo, en Cartagena, cuya ordenanza de carpinteros data de finales del XVI, se especifica "que el quisiere ser examinado de maestro, haya de presentar certificación del maestro conque hubiere aprendido de haber trabajado, siete años de aprendiz y tres de oficial", además de que "los oficiales y aprendices han de ser de buenas costumbres y limpios de toda mala raza" (Cañabate, 1962: 95).

Con este control gremial sobre el aprendizaje y el trabajo es imposible que, en el siglo XVI y principios del XVII se establecieran, y de manera permanente, en el territorio murciano carpinteros con la categoría de "iumétrico" o de "lazero", a pesar del gran número de edificios, especialmente religiosos, que se construyen con techumbres de madera con lacería. En el caso de las techumbres murcianas, seguramente la falta de mano de obra experimentada en trabajos de cantería (que se concentraba en la construcción de la Catedral de Murcia), y la necesidad de construir con rapidez y a bajo coste, hizo que se empleara preferentemente el sistema estructural de arcos transversales, ahorrando los costosos apeos de otros sistemas constructivos, como el abovedado. El sistema de pares y nudillo, con el uso de la lima doble o mohamar en el encuentro de los faldones; solución que para Nuere (2015: 1225) es una de las grandes aportaciones de la carpintería nazarí a la castellana, pues esta solución no existe en la carpintería europea; permitirá la prefabricación, en taller y por partes, de la techumbre, permitiendo al carpintero desarrollar la lacería. Por ello, la típica ornamentación basada en estrellas y dibujos geométricos que se van formando con líneas que se entrecruzan, pasando alternativamente unas por encima de las otras (la regla de "corta y pasa"), formando y entrelazando diferentes figuras poligonales la encontramos en el almizate (o harneruelo, la parte horizontal, y por ello más visible, de las techumbres) y en las cubiertas resueltas con el sistema de par y nudillo. Y lógicamente, estos trabajos debieron realizarlos talleres de 
carpinteros, muy probablemente procedentes de áreas castellanas (como se ha comentado), bajo la dirección de un maestro con la categoría de "iométrico", si tenemos en cuenta la calidad técnica de las carpinterías de lazo que se conservan en las techumbres de Caravaca, Cehegín, Totana...

Por tanto, la larga tradición medieval de movilidad de los talleres de artesanos dedicados a la construcción de iglesias; tendrá su reflejo en estas techumbres. Como prueba de esto, en Lorca está acreditada la autoría del carpintero Esteban Riberón en las techumbres de los conventos de Santo Domingo y de La Merced, y en las ermitas de Santa Quiteria y San Lázaro, además de realizar, entre 1560 y 1576, la magnífica armadura de par y nudillo de la iglesia de Santiago, en Totana (Belda y Marín, 1999). Y la techumbre del santuario de Santa Eulalia de Mérida, en Totana, se atribuye al taller de Riberón, pues se trata de una reproducción, en pequeño, de la armadura de Santiago y se termina hacia 1595, cinco años después del fallecimiento de Riberón. La techumbre de la iglesia de San Onofre, en Alguazas, se atribuye a los carpinteros conquenses Antonio Martínez y Bartolomé Hernandez, participando un Bartolomé Hernández (posiblemente el mismo) en las techumbres del convento de La Merced, en Lorca, y en la iglesia de San Antonio, en Murcia, En el caso de la iglesia de La Purísima Concepción, en Caravaca, está acreditada la autoría del trabajo al carpintero Baltasar de Molina (Collado, 2020: 275), y la participación de los carpinteros Juan y Ginés Miravete y Diego Pérez. Por desgracia, en Cehegín los libros de fábrica y los libros de cuentas de la Cofradía de Ntra. Sra. de La Concepción no se han conservado, por lo que no se puede acreditar el autor de la magnífica armadura ochava de la iglesia. Sin embargo, y teniendo en cuenta la constante "relación" entre las iglesias de La Concepción de Caravaca y Cehegín (Collado 2018, 2020 y 2021), la hipótesis de la participación de Baltasar de Molina y/o de su taller de carpintería en esta techumbre podría considerarse hasta lógica.

En cuanto al empleo del término "artesonado" para definir estas techumbres (muy extendido a nivel popular), debemos aclarar que realmente un artesonado es una tipología de forjado (estructura horizontal) formado por vigas de madera acodaladas, que forman recuadros más o menos regulares y que solían enriquecerse con diferentes tipos de molduras y policromía. La imagen general es la de un conjunto regular de "cajones o casetones" de madera colocados boca abajo, es decir, artesas invertidas (de ahí el nombre de artesonado). Esta solución, que es estructural y decorativa, será muy utilizada en el Renacimiento para ornamentar palacios y villas burguesas, aunque en la Región de Murcia los numerosos y vistosos ejemplos de esta tipología corresponden a edificios con decoración modernista, como podemos ver en varias salas del Real Casino de Murcia o las Casas Consistoriales de Mazarrón (destacando el Salón de Plenos). Sin embargo, hay que tener en cuenta que los casetones que conforman la decoración en estos ejemplos murcianos son de escayola y únicamente la estructura acodalada de las vigas es de madera. Un buen ejemplo de artesonado de madera es el techo del Salón Dorado del Palacio de la Generalitat, en Valencia. Por tanto, y para ser rigurosos, cuando nos referimos a techumbres de madera resueltas con armadura o carpintería de armar, tengan o no decoración de lazo, no deberíamos emplear el término "artesonado", y en el caso concreto de las techumbres murcianas con desarrollo de lacería lo correcto sería hablar de "carpintería de lazo", como denomina estas tipologías el arquitecto Enrique Nuere (2010:46).

\section{LA INFLUENCIA CASTELLANA, LEVANTINA Y/O GRANADINA}

En 1960, el profesor Alfonso E. Pérez Sánchez publica "Iglesias mudéjares del Reino de Murcia", texto que se convierte en el principal referente documental para conocer y clasificar la mayoría de los templos murcianos con techumbres de madera resueltas con carpintería de armar, con o sin decoración de lacería. Es un breve e incompleto estudio-catálogo que incluye el análisis de diecisiete "iglesias mudéjares", en su mayoría construidas en el siglo XVI, que incluye cinco templos de la provincia de Albacete pero que en esa época se integraban en el Reino de Murcia (San Antón, en Albacete, San Julián y el convento de Santo Domingo, en Chinchilla, San Sebastián, en Villapalacios y la torre de Santa María, en Villarobledo); con referencias a varias iglesias/ermitas murcianas que, por desgracia, no han conservado las 
techumbres de madera, y ninguna referencia a la iglesia de Ntra Sra. de Loreto, en AlgezaresMurcia, ni a la ermita de San Sebastián, en Caravaca (entre las ausencias más destacadas). El texto incluye afirmaciones como que "las techumbres son siempre y casi sin excepción de carácter mudéjar" (Pérez, 1960: 93), o que "en Murcia, la vinculación a Granada de las cubiertas que se conservan es evidentemente directísima" (1960: 103); 1legando a poner en cuestión la influencia de los constructores valencianos al incidir en que "una doble influencia se manifiesta: la levantina (valenciana) y la andaluza. Tormo (Levante, 1923), quizá exagere su relación de dependencia con lo valenciano. Un análisis más detenido lleva a pensar mejor en lo granadino, tanto más próximo también, pues en el XVI el contacto entre Granada y Murcia es intenso a través de una Almería, feudo de los murcianos Faxardos" (1960: 92). Por tanto, y tomando como referencia estas conclusiones, varios textos posteriores de autores murcianos asumían la influencia granadina (arquitectura y diseño nazarí, musulmán) en las techumbres de madera de nuestra Región.

Para el valenciano Elías Tormo Monzó, que denominó "arquitectura de reconquista" este tipo de construcciones, es clara la influencia valenciana en las techumbres murcianas, especialmente cuando nos referimos a los templos resueltos con arcos transversales o diafragma, por ser esta solución estructural y constructiva, tardogótica, la que se impuso para levantar la mayoría de parroquias, capillas, ermitas e iglesias de conventos mendicantes en el Reino de Valencia en esta época (Zaragozá, 2017; 142), algo que Pérez Sánchez pone muy en duda. También Torres Balbás defendía la influencia valenciana en las construcciones murcianas, especialmente para las iglesias de arcos transversales, así como para los templos granadinos con esta solución estructural: "el tipo de templo más propagado por la región levantina (...) es el de nave cortada por arcos fajones transversales, trasdosados en forma angular para el asiento de la armadura de madera a dos aguas que cubre aquella. Casi siempre se abren capillas entre los contrafuertes. El presbiterio es cuadrado o rectangular y cubierto también con madera. (...) y nada deben al arte islámico. La única influencia mudéjar que existe en semejantes iglesias levantinas, hay que buscarla tan solo en las pinturas que decoran su techumbre a dos aguas. Tal vez desde Levante este tipo de templos llegó a Granada en el siglo XVI a raiz de su conquista" (Torres, 1949: 295), teniendo en cuenta que para este autor Murcia formaría parte de la "región levantina", aunque el Reino de Valencia perteneció a la Corona de Aragón y el Reino de Murcia a la Corona de Castilla.

Pero hay que tener en cuenta que el sistema de arcos transversales o diafragma no puede considerarse como algo propio y que exporta el Reino de Valencia. Es un sistema constructivo que desarrolla la arquitectura romana, la arquitectura bizantina la extiende por el Mediterráneo y durante los siglos XIV y XV será el más utilizado, por su facilidad constructiva y ahorro de medios (especialmente de madera para andamiajes y techumbres), por las diferentes órdenes mendicantes y la iglesia diocesana del Reino de Valencia. Con este modelo, se desarrolla una extensa red de parroquias, iglesias y ermitas que permiten articular y organizar religiosa, social y administrativamente el territorio valenciano; y para ello se recurrirá a cuadrillas de artesanos itinerantes (Zaragozá, 2017: 138-142), con lo que se repetirán tipologías constructivas y soluciones decorativas, tanto en estructuras como en las techumbres de madera. Por tanto, el modelo estructural de arcos transversales o diafragma será el más utilizado por las órdenes militares, especialmente para levantar templos "menores", como las ermitas, y la proliferación de este sistema en el Reino de Valencia (Corona de Aragón), no puede implicar que las ermitas/ iglesias murcianas (Corona de Castilla), se construyeran bajo la influencia valenciana. Además, la participación de cuadrillas itinerantes de canteros, albañiles y carpinteros valencianos implica el uso de la vara valenciana (que equivale a 90,60 cm) como patrón de medida y traza de los templos y, según se ha podido comprobar, la vara castellana o de Burgos (que equivale a 83,59 cm) es la utilizada preferentemente en los templos murcianos (Collado, 2019 y 2021); aunque esta afirmación debe tomarse con las reservas propias de la falta de exactitud de las medidas actuales de las construcciones por las reformas realizadas, en algunos casos, y por la propia naturaleza de los medios utilizados en origen: una vara o regla graduada y un compás.

En 1987, la profesora Cristina Gutiérrez-Cortines publica su excelente tesis doctoral sobre arquitectura religiosa renacentista en la antigua Diócesis de Cartagena que incluye un extenso capítulo dedicado a analizar "las iglesias de techumbre de madera" (GutiérrezCortines, 1987), y en el que incide en la idea de la influencia andaluza más que en la valenciana. En el caso de la iglesia de Ntra. Sra. de la Concepción, en Cehegín, defiende que "en su forma 
y decoración en esta techumbre se advierte una fuerte influencia andaluza" (1987: 459), y sobre los templos lorquinos que "si existió una tradición mudéjar en Lorca, seguramente estuvo entroncada con las corrientes granadinas o cordobesas, más que con las tendencias valencianas, que llegarían a esta área como producto de segunda mano" (1987: 468).

Por todo esto, tradicionalmente se han tomado los modelos constructivos y la tipología estilística de las techumbres de madera, con lacería, del reino nazarí de Granada como la fuente para entender las cubiertas murcianas. En cualquier caso, para intentar determinar qué modelos tipológico-constructivos y estilísticos podrían haber influido en los diseños de los templos murcianos del XVI debemos analizar cómo fueron desarrollándose estos modelos conforme avanzaba la reconquista cristiana de la Península.

La presencia musulmana en la Península Ibérica comprende desde el siglo VIII (entrada y creación de al-Ándalus en el año 711) hasta el siglo XV (toma de Granada, en 1492), ocho siglos de enfrentamientos que, a partir de la capitulación de Toledo, en 1085, convierten a esta ciudad, donde convivirán musulmanes (ahora mudéjares), cristianos y judíos, en símbolo y referente para las nuevas construcciones de la Corona de Castilla. El proceso de reconquista cristiana será muy lento $\mathrm{y}$, al mismo tiempo que se van reincorporando territorios, se irá produciendo una asimilación de población musulmana que conllevará un intercambio de conocimientos y técnicas, así como colaboración laboral, entre musulmanes y cristianos que, en el ámbito de la construcción, significó el desarrollo de lo que se ha denominado como "arquitectura mudéjar". Dependiendo de las características de cada territorio reconquistado se irán configurando "centros artísticos" cuya influencia se dejará notar en diferentes ámbitos geográficos, destacando la influencia de las tipologías toledanas, para el territorio castellano, y el mudéjar aragonés (valle del Ebro, Zaragoza y Teruel) para los territorios de la Corona de Aragón.

La tipología toledana, cuyos maestros y carpinteros siempre mantuvieron contacto con el territorio andaluz (Córdoba será reconquistada en 1236 y Sevilla en 1248) y el reino nazarí de Granada, se caracterizó por "el uso sistemático y casi exclusivo de la estrella de ocho como base de sus trazados. (...) La estrella de ocho puntas y el lazo sirven de herramienta compositiva que abarca desde las armaduras más antiguas hasta los artesonados renacentistas" (Nuere et al., 2019). Como sabemos, las lacerías de las techumbres murcianas desarrollan también exclusivamente la estrella de ocho, un ejemplo claro de la influencia castellana. El templo mudéjar sevillano tipo será de tres naves, sobre arcos apuntados y se cubrirá con armadura de par y nudillo, con lacería (predominando la estrella de ocho) en la nave central y colgadizo en laterales (la iglesia de Santiago, en Totana, podría ser de este tipo, salvo por el uso de arcos de medio punto). Como la iglesia de San Andrés, en Mazarrón, y la ermita de Santa Eulalia de Mérida se cubren con armadura de par y nudillo, en varios textos aparecen como ejemplos murcianos de modelos andaluces, olvidando la gran cantidad de iglesias castellanas y granadinas con esta tipología constructiva de techumbre de madera. Además, como comenta Pérez Sánchez, una vez reconquistado el territorio granadino, en las nuevas techumbres con armadura de par y nudillo, realizadas por carpinteros procedentes de Castilla, desaparece el mocárabe (elemento fundamental en la decoración nazarí) y las maderas se dejan en su color natural (como en Totana), a diferencia de las techumbres de los territorios castellanos que están ricamente policromadas (1960: 103).

Elmudéjar aragonés se caracterizará por la utilización predominante delladrillo aplantillado como elemento constructivo y ornamental, frente a la cantería, y menos uso, inicialmente, de la techumbre de madera; pasando del sistema abovedado al uso de la armadura de madera de par y nudillo, con tirantes, de claro origen almohade (García y Cánovas, 2018; 132), principalmente en Teruel, fruto también de este intercambio de conocimientos entre territorios.

Por tanto, y como defiende Nuere, será la convivencia hispanomusulmana la que aportará estos nuevos conceptos formales, estéticos y compositivos que, principalmente los carpinteros castellanos, fueron capaces de incorporar a sus trabajos gracias al dominio que tenían de la técnica constructiva de las armaduras de madera en cubiertas. Para Enrique Nuere "fueron los carpinteros castellanos quienes sistemáticamente integraron la decoración típicamente islámica en sus armaduras de cubierta, mientras los nazaries preferían emplear su característica geometría principalmente con funciones decorativas, lo que no impedía que en alguna ocasión también la emplearan en carpinterías estructurales" (Nuere, 2010: 32). El resultado son las techumbres que se desarrollaron en toda la Península, llegando a las Canarias, al norte 
de África y a Iberoamérica. Unos trabajos de mucha calidad técnica y que, dependiendo de la zona geográfica, irá desarrollando algunas particularidades. Así, las techumbres nazaríes (principalmente concentradas en Granada) y las de Toledo tendrán sus zonas de influencia; y las que se desarrollen en el archipiélago canario o las construidas en Iberoamérica (realizadas por carpinteros castellanos) también tendrán sus características y rasgos diferenciadores.

La techumbre de Cehegín, por su singularidad en el territorio murciano, ha sido analizada por varios historiadores llegando a remitir su diseño y tipología constructiva " $a$ modelos extremeños, relacionados con órdenes militares, del siglo XIV en que se utilizaba el sistema de arcos transversales y tres naves con, aproximadamente, triple anchura y mayor altura la central" (López, 2016: 374). La relación 2:1 entre nave central y laterales, fue la más común en el territorio murciano en el XVI, sin embargo, en Cehegín su utilizó la relación 3:1. Pero hay que tener muy en cuenta que estos "modelos extremeños" se caracterizan por la fuerte influencia tipológica de las construcciones toledanas, pues el territorio extremeño dependía de la Diócesis de Toledo y estaba controlado por la Corona de Castilla a través de la Orden Militar de Santiago, como ocurría en el Reino de Murcia. Además, en la construcción de este templo está acreditada la dirección del maestro cantero Martín de Homa, de origen vizcaíno y que trabajó en varias ocasiones en reparaciones en las murallas de Cehegín (Gutiérrez-Cortines, 1987: 453) y en las iglesias de El Salvador y La Concepción, en Caravaca. Por tanto, la influencia de los "modelos extremeños" no sería aceptable, siendo más lógica la correspondencia con tipologías constructivas castellanas y bajo la supervisión de la Orden de Santiago.

\section{ALGUNAS CONCLUSIONES}

Con la reconquista cristiana del reino nazarí de Granada, en 1492, el Reino de Murcia deja de ser zona fronteriza e insegura e inicia un periodo de estabilidad social y notable aumento de población. Esto conllevará el crecimiento extramuros de ciudades como Caravaca de la Cruz, Cehegín, Lorca, Totana..., y la construcción de numerosas iglesias para cubrir las necesidades de la población y facilitar la evangelización y asimilación sociocultural de la población musulmana, a la que ahora se identificará como "morisca".

En general, estos nuevos templos serán levantados con materiales y sistemas constructivos propios de la llamada "arquitectura tradicional popular", usando materiales del entorno como la tierra compactada, cal, madera de pino, ladrillo y mampostería. Serán de planta rectangular y dimensiones reducidas, con una nave central amplia y laterales estrechas, poco iluminadas, cubierta a dos aguas y fachadas lisas y austeras, con pocos elementos ornamentales. Y lo más singular, característico y destacable de estas construcciones será el sistema de techumbre de madera a base de carpintería de armar con lacería.
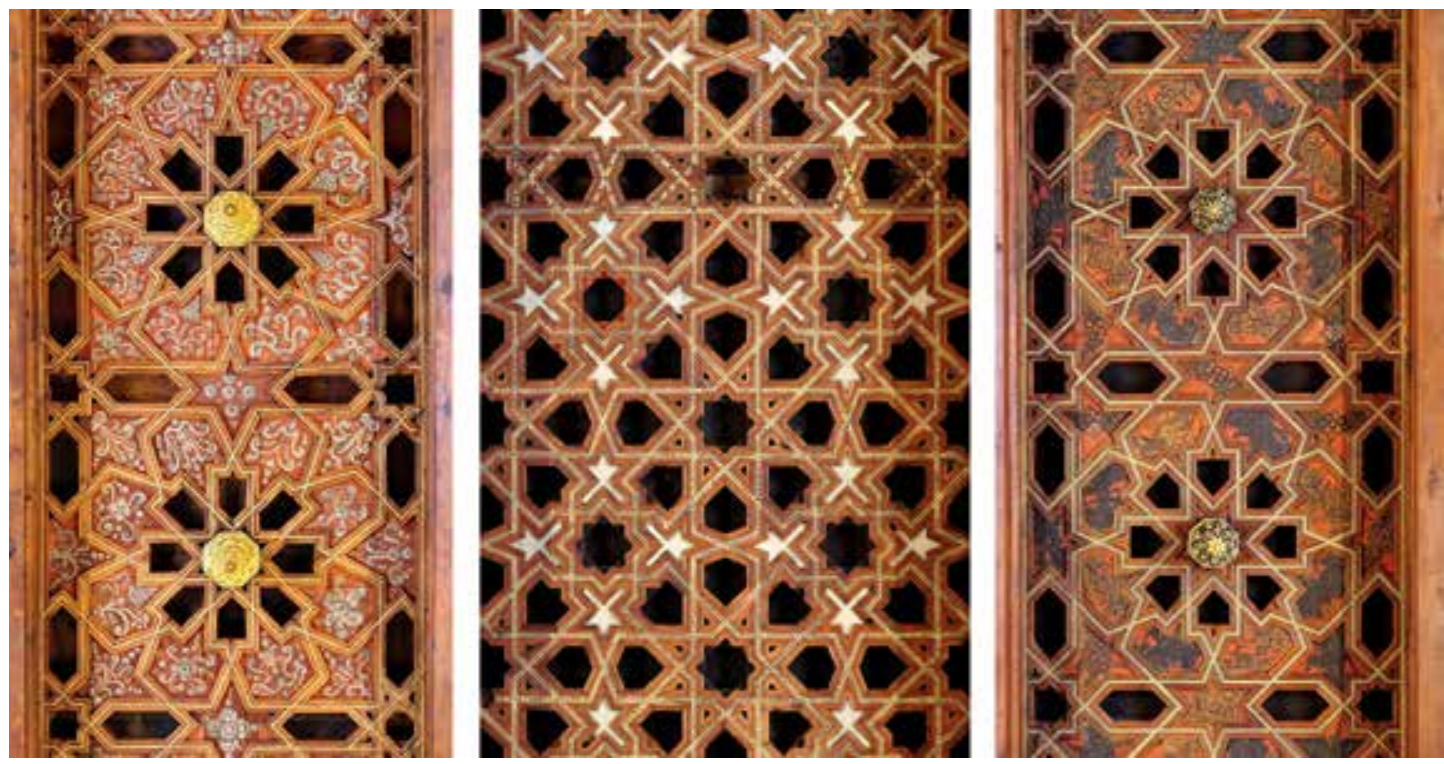

FIGURA 4. Detalles de la carpintería de lazo, con estrella de ocho puntas, de tres de los almizates de la techumbre de madera de la Iglesia de La Purísima Concepción, en Caravaca de la Cruz. 
Desde que en 1960 se publicara un breve e incompleto estudio-catálogo, con el título "Iglesias mudéjares del Reino de Murcia”, en el que se exponen las características de estas construcciones, hasta la actualidad se ha producido un creciente interés por analizar y dar a conocer estos trabajos de carpintería de armar. Se han publicado varios estudios científicos, muy interesantes, aunque centrados especialmente en aspectos históricos, artísticos y tipológicos de estas techumbres, dejando un poco al margen los aspectos formales y constructivos (trazado, técnicas de desarrollo y ensamblaje...). Además, a estas construcciones históricas se les ha denominado como "iglesias mudéjares" o "iglesias moriscas". Sin embargo, si se analiza el contexto histórico y sociocultural en que se realizaron estas construcciones y las condiciones laborales (bajo el control de los gremios de carpinteros y regulado por las correspondientes ordenanzas), de los alarifes, maestros de obras, oficiales, carpinteros, pintores y aprendices que levantaban estas iglesias, la participación de carpinteros mudéjares y/o moriscos en la realización de las techumbres de madera es más que improbable. Por tanto, el concepto "iglesia mudéjar" o "techumbre mudéjar" con el que popular y erróneamente se suelen definir las iglesias del siglo XVI del Reino de Murcia, sólo sería aceptable si se hace en base al estilo artístico y no como referencia a los maestros carpinteros autores de estos trabajos. Lo más probable es que estas techumbres fueran realizadas por talleres de carpinteros, procedentes de áreas castellanas y bajo la dirección de un maestro con la categoría de "iométrico", si tenemos en cuenta la calidad técnica de las carpinterías de lazo que se conservan en las techumbres de las iglesias de la Purísima Concepción, en Caravaca, Ntra. Sra. de la Concepción, en Cehegín, Santiago, en Totana, San Andrés, en Mazarrón, San Onofre, en Alguazas o Santa Eulalia de Mérida, también en Totana, por hablar de los ejemplos más representativos y vistosos de los que aún se conservan en nuestra Región. Por desgracia, la documentación histórica (libros de fábrica y libros de cuentas de las cofradías) es muy escasa y solo conocemos algunos nombres de carpinteros que trabajaron en el siglo XVI en el trazado y construcción de estas techumbres, como Esteban Riberón, Baltasar de Molina, Antonio Martínez y Bartolomé Hernández; especialmente los dos primeros debían tener el grado de "iumétrico" (máxima categoría que podía alcanzar un carpintero de lo blanco), a tenor de la calidad de las techumbres cuya autoría está documentada.

Dependiendo del autor que las analizara, las techumbres murcianas han sido relacionadas con los modelos granadinos, sevillanos, levantinos (por el uso de arcos transversales o diafragma), extremeños y castellanos. Pero teniendo en cuenta, por ejemplo, que el modelo estructural de arcos transversales o diafragma será el más utilizado por las órdenes militares (el Reino de Murcia dependerá, especialmente, de la Orden de Santiago) para levantar templos "menores", como las ermitas, el uso predominante de este sistema constructivo en el levante (Corona de Aragón), no puede implicar que las ermitas/iglesias murcianas (Corona de Castilla), se construyeran bajo la influencia valenciana. El uso de la estrella de ocho como base para desarrollar la lacería en los almizates y estructuras de par y nudillo de los templos murcianos muestran una clara influencia castellana, pues este sistema estructural y decorativo fue "exportado" por los carpinteros toledanos al territorio andaluz, inicialmente a Sevilla y, con la reconquista, al Reino de Granada. Además, el patrón de medida y traza de los templos murcianos es la vara castellana o de Burgos, por lo que la influencia castellana y la procedencia de los carpinteros de esos territorios es más que una hipótesis.

Esperemos que este texto haya servido para aclarar conceptos básicos y ayudar a definir las características tipológicas, materiales y compositivas de las techumbres de madera, con soluciones estructurales y decorativas de carpintería de armar con lacería, que afortunadamente aún se conservan en la Región de Murcia, contribuyendo así a su reconocimiento y puesta en valor. 


\section{REFERENCIAS BIBLIOGRÁFICAS}

- Belda Iniesta, M.T. y Marín Torres, M.T. (1999) Las techumbres mudéjares de Lorca en el siglo XVI. En Clavis. Lorca: Ayuntamiento de Lorca, 103-118.

- Belda Navarro, C. y Hernández Albaladejo, E. (2006). Arte en la Región de Murcia. De la Reconquista a la Ilustración. Murcia: Colección Monografías Regionales nº6. Editora Regional de Murcia.

- Borrás Gualis, G.M. (2006). Estructuras mudéjares aragonesas. En Arte mudéjar en Aragón, León, Castilla, Extremadura y Andalucía. Zaragoza: Institución "Fernando el Católico" (C.S.I.C.), 297-313.

- Cantero Mancebo, S. (2011). Techumbres históricas de estilo mudéjar en los templos murcianos. Estado de la cuestión. En XXII Jornadas de Patrimonio Cultural de la Región de Murcia. Murcia: Tres Fronteras Ediciones. Murcia, 139-148.

- Cañabate Navarro, E. (1962). Ordenanza de los gremios de Cartagena en el siglo XVIII. En MVRGETANA $n^{\circ}$ 18. Murcia: Real Academia Alfonso X El Sabio, 51-97.

- Collado Espejo, P.E. y Fernández del Toro, J. (2018). La carpintería de armar en las iglesias de La Concepción de Caravaca, Cehegín y Mula. En XXIV Jornadas de Patrimonio Cultural de la Región de Murcia. Murcia: Tres Fronteras Ediciones, 173-180.

- Collado Espejo, P.E. (2019). Análisis formal y constructivo de la armadura de par y nudillo con lacería de la Iglesia de Ntra. Sra. de La Concepción de Cehegín. En XXV Jornadas de Patrimonio Cultural de la Región de Murcia. Murcia: Tres Fronteras Ediciones, 303-310.

- Collado Espejo, P.E. (2020). Análisis formal y constructivo de la techumbre decorada con lacería de la Iglesia Parroquial de la Purísima Concepción, en Caravaca de la Cruz. En XXVI Jornadas de Patrimonio Cultural de la Región de Murcia. Murcia: Tres Fronteras Ediciones, 273-280.

- Collado Espejo, P.E. (2020). La estrella de ocho en la carpintería de lazo. La Iglesia Parroquial de La Purísima Concepción, en Caravaca de la Cruz, como ejemplo. En Anuario 3. Colección Docencia, Innovación, Investigación. Dpto. de Arquitectura y Tecnología de la Edificación UPCT 2019.2020. Cartagena: CRAI Biblioteca UPCT, 138-147

- Collado Espejo, P.E. (2021). Análisis técnico-constructivo de la armadura de lazo del presbiterio de la Iglesia de Ntra. Sra. de La Concepción (Cehegín, Región de Murcia). En Alquipir, $n^{\circ} 16$. Cehegín: Ayuntamiento de Cehegín, pp. 11-25.

- De la Ossa Giménez, E. y López Martínez, M.C. (1993) Arquitectura popular religiosa en la Comarca del Noroeste: las ermitas. En VERDOLAY, $n^{\circ} 4$. Murcia: Museo de Murcia, 237-244.

- De la Ossa Giménez, E. (1998). Los gozos y las sombras de San Ramón Nonato y el retablo pintado de la ermita de la Concepción de Cehegín (Murcia). En IMAFRONTE, 12-13. Murcia: Universidad de Murcia, 227-240.

- García Zapata, I.J. y Cánovas Belchí, J.T. (2018). Arte hispanomusulmán y mudéjar. Murcia: Servicio de Publicaciones de la Universidad de Murcia.

- Gutiérrez-Cortines Corral, C. (1987). Cap. VII. Las iglesias de techumbre de madera. En Renacimiento y arquitectura religiosa en la antigua Diócesis de Cartagena (Reyno de Murcia, Gobernación de Orihuela y Sierra del Segura). Murcia: Colegio Oficial de Aparejadores y Arquitectos Técnicos de Murcia, 435-479.

- Gutiérrez-Cortines Corral, C. y Griñán Montealegre, M. (1996). La devoción en el espacio: las ermitas en los territorios de las Órdenes Militares. En IMAFRONTE, $n^{\circ} 10$. Murcia: Universidad de Murcia, 51-60.

- López Guzmán, R. (2016, $3^{\circ}$ edición). Arquitectura mudéjar. Madrid: Ediciones Cátedra.

- Marín Sánchez, R. (1999). El uso de dovelas de mortero de yeso en arcos. Bases para un estudio. En ALQUIPIR, no $n^{\circ}$-9. Cehegín: Ayuntamiento de Cehegín, 13-22.

- Molina Molina, A.L. (2002). Evolución urbana de Cehegín: de la Edad Media a 1850. En Estudios históricos y geográficos para la recuperación de los cascos históricos del Noroeste de la Región de Murcia. Murcia: Universidad de Murcia, 123-142.

- Molina Molina, A.L. (2014). De mudéjares a moriscos: el ejemplo de Murcia. En Murgetana, $n^{\circ}$ 131. Murcia: Real Academia Alfonso X El Sabio, 187-202.

- Nuere Matauco, E. (2000). La carpintería de armar española. Madrid: Editorial Munilla-Lería.

- Nuere Matauco, E. (2010). Dibujo, geometría y carpinteros en la arquitectura. Madrid: Real Academia de Bellas Artes de San Fernando. (Discurso de ingreso).

- Nuere Matauco, E. (2015). El origen de la carpintería de lazo. En Seminario Internacional 
Arquitectura y Humanismo. Madrid: Mairea Libros, 134-137.

- Nuere Matauco, E. (2015). Carpintería ¿̇mudéjar?. Castilla y León crisol de culturas. En Actas del Noveno Congreso Nacional y Primer Congreso Internacional Hispanoamericano de Historia de la Construcción. Vol. 3. Madrid: Instituto Juan de Herrera, 1215-1226.

- Nuere Matauco, E.; Franco Rodríguez, E. y Fernández Cabo, M.C. (2019). Armaduras de lazo toledanas. Evolución de las trazas geométricas con estrellas de ocho puntas y su relación con los diferentes sistemas constructivos empleados. En Informes de la Construcción, 71 (556): e317. Madrid.

- Pérez Sánchez, A.E. (1960). Iglesias mudéjares del Reino de Murcia. En Arte Español, vol. 23. Madrid: Revista Española de la Sociedad de Amigos del Arte, 91-112.

- R.D. 2430/1980, de 3 de octubre, por el que se declara monumento histórico-artístico, de carácter nacional, la iglesia de la Concepción de Cehegín (Murcia). BOE $\mathrm{n}^{\circ}$ 270, de 10 de noviembre de 1980; p. 25108. (Con la aprobación de la Ley 16/1985 del Patrimonio Histórico Español, pasa a ser B.I.C. con categoría de Monumento).

- DECRETO no26/1995, de 28 de abril del Consejo de Gobierno de la Comunidad Autónoma de la Región de Murcia, por el que se declara bien de interés cultural, con categoría de monumento, la Iglesia Parroquial de Nuestra Señora de Loreto, en Algezares (Murcia). BOE n 123, de 29 de mayo de 1995.

- Torres Balbás, L. (1949). Arte almohade. Arte nazarí. Arte mudéjar. En Historia Universal del Arte Hispánico. Vol. Cuarto. Madrid: Plus Ultra.

- Zaragozá Catalán, A. (2017) Las Iglesias de arcos de diafragma y techumbre de madera en el levante hispánico. En Pax Christi 1505-2002 V Centenario de la fundación de las parroquias del Valle de Ricote. Murcia: Consejería de Cultura, Juventud y Deportes, 138-151. 